\section{A SPECIAL DIAGNOSTIC PHENOMENON IN CEREBELLAR DISEASES.}

\section{REPORT OF SIX CASES, FOUR OF WHICH CAME TO} AUTOPSY.*

ALFRED GORDON, M.D.

Associate In Nervous and Mental Diseases, Jefferson Medical College Neurologist to the Douglass Memorial Hospital and Mount Sinal Hospital. PHILADELPHIA.

A localizing diagnosis of cerebellar diseases presents at times some difficulty. Among all the symptoms, palsies of cranial nerves are very important, but when they are absent the determination of the seat of the lesion becomes embarrassing. Certain attitudes of the body, and especially of the head, may be present in some eases, and when they do occur they are of considerable assistance in localizing the lesion.

The following six cases have been studied by me from the latter standpoint. The correct diagnosis of four cases was verified on postmortem examination. The other two presented the classical symptom-group of cerebellar tumors. The special phenomenon to which I wish to call special attention was present in each of the cases. The inference drawn as to the seat of the tumor was corroborated postmortem.

CASE 1.-History.-William R., aged 12 ; five years ago began to show symptoms of gastrointestinal disorder. There were occasional nausea, eructations, aversion for certain articles of food and also slight healache. For months he was considered a dyspeptic and treated accordingly. Then the headache grad. ually increased and vomiting made its appearance. Soon the c.lild commenced to complain of dimness of vision. Dr. W. W Keen was first consulted in 1904 and he referred the patient to me for an opinion. At that time $\mathrm{I}$ made the following observation: The headache was excruciating, vomiting was frequent, the gait distinctly cerebellar (titubation) with a tendency to walk towards the left. Blindness was partial The knee-jerks were abolished on both sides. The Babinski sign was present on the right side and paradoxical reflex on both sides. The lower part of the face was deviated to the right. The pupils were unequal, the left the largest. Nystag mus was marked on lateral movements of the eyes especially when the latter were turned to the left. The eye-grounds showed choked disks on both sides, more on the left than on the right. Gradually the condition became worse. The patient's headache got unusually intense, he lost the power of locomotion, had frequent attacks of vomiting, became totally blind and the head was held inclined on the left side.

Diagnosis.-Cerebellar neoplasm, probably on the left side.

Treatment. $\rightarrow$ A course of treatment with iodids gradually improved the condition so that at the end of a few months he was free from headache and vomiting. The suffering disappeared, but the blindness remained. The little patient was able to walk, his sleep, appetite and digestion were excellent. The head remained inclined to the lefu side, the left facial palsy was unaltered.

Subsequent History.-After a period of two years the symptoms began to return. The following symptoms were then observed: Headache, but no vomiting, total blindness, deafness of the left ear, paralysis of the external recti, more in the left eye than in the right, nystagmus more on movement of the eye to the left than to the right, inability to walk or stand, but no paralysis of the limbs; the knee-jerk abolished, Babinski sign and paradoxical reflexes present on both sides. Sensations were normal. The striking symptom was the unavoidable necessity for the patient to hold his face turned to the right side, as whenever he or any one would turn it io the left, a most intense vertigo would appear. At this stage $v_{i}$ the disease the position of the head changed, viz., from the

* Read before the American Neurological Association, May 20 1008, in Prilatelphia. left to the right and remained in this position until the enci, but the appearance of vertigo on turning the face to the left made the association very important. The change in the position of the head appeared six months before the patient died.

Autopsy.-The autopsy showed a soft tumor in the left cerebellar hemisphere pressing partly on the vermis and forward on the superior cerebellar peduncles. No permission was granted by the relatives to remove the specimen for microscopic examination.

CASE 2.-History.-S. M., girl, aged 9, with good family and personal histories, fell down a flight of thirteen steps, striking her head. She was not unconscious, but bled considerably from the nose, and vomited. Two days later she vomited again and kept on vomiting almost daily until death, viz., for a period of five months. During all that time she suffered from severe headache. Two wetks after the accident she began to hold her head forward and inclined to the right. An attempt to turn the head to the left produced an intense vertigo which was immediately relieved when the head was placed in the former position.

Examination.-On examination, I found the position of the head as described above, maxked titubation with a slight tendency to fall towards the left, increased knee-jerks, and paradoxical reflex on the left. The eyes at that time, viz., two months after the accident were normal except for a dilatation of the pupils. In spite of the absence of characteristic eyesymptoms my diagnosis was that of a cerebellar tumor and probably on the left side. Subsequent events proved it to be correct. Two and a half months later the eye examination showed the pupils slightly responsive to light, but not to accommodation nor to convergence; right optic nerve hyperemic an 1 retinal veins tortuous and overfilled; left optic neuritis low in grade, but acute, neighboring retina edematous. At the same time the headache increased and the vertigo on turning the head to the left was intense. The vomiting continued. The patient grew worse and one morning she was found dead. In this case the peculiar position of the head appeared immediately after the severe symptoms set. in.

Autopsy.-The dura was tense over the entire brain especially on the left side posteriorly. There was an excess of fluid at the base. Projecting from the lower aspect of the left lobe of the cerebellum was a mass, grayish in color and very fragile, the outer portion being as soft as brain substance. The growth extended from slightly across the median line to the right outward at a distance of $6 \mathrm{~cm}$. Anteroposteriorly it was $\tilde{\mathbf{5}} \mathbf{c m}$. in extent at the point of attachment. It attain an elevation of $4 \mathrm{~cm}$. A portion of it was adherent to the dura and separated by its own weight from the underlying portion of the growth. The growth extended for some distance into the cerebellar lobe to which it was quite loosely attached. Microscopically the tumor proved to be tuberculous. (See illustration.)

CASE 3.-History.-S. L., man, aged, 35, presented the folJowing symptoms: Vertigo, vomiting, occipital headache, and diplopia.

Examination.-There was marked titubation with a tendency to fall towards the right, nystagmus on lateral move ments of the eyes, diminished knee-jerks, right hemi-asynergy and inclination of the head toward the left. The fundi of the eyes showed choked disk on the right, congestion on the left. The headache was intense. An operation was declined by the patient and his relatives. He left the hospital. Two months later I saw him and found the condition unchanged. The position of the head toward the left was fixed and the slightest attempt to turn it to the right produced an intensc vertigo. I have had no opportunity to see him since. In this case the special position of the head remained unchanged during the entire time of observation, viz., five months.

CASE 4.-History.-W. L., man, aged 49, was admitted to the Jefferson Hospital during summer 1906. He complained of severe frontal headache, vertigo and vomiting. Titubation, nystagmus, loss of knee-jerks with Babinski's sign and double optic neuritis were the other signs of presumable cerebellar disease. The head was drawn backward with a 
slight inclination towards the left, but when it was turned to the right, vertigo became intense. The patient died and no autopsy was allowed. The special attitude of the head remained unaltered during the six weeks of observation at the hospital and according to the patient's relatives, had been noticed from the beginning of the disease.

CASE 5.-History.-S. G., married worian, aged 29, was treated for two years for gastric trouble, accompanied by nausea and vomiting. She then sustained an accidental injury, falling off a car. Soon violent headache developed which was confined to the left side of the forehead. The vomiting became more frequent. I saw her six weeks after the injury and she presented in addition to the above symptoms distinct titubation with a tendency to fall toward the left, diminished reflexes, nystagmus on movements of the eyeballs to the left and partial blindness. The eye-grounds showed choked disk on the left and optic neuritis on the right. The head was inclined to the right and the least attempt to turn it to the opposite side caused an intense vertigo and nausea. The patient died and a soft tumor was found in the left cerebellar lobe directed downward and forward. The husbanil strongly objected to the removal of a smallest portion of ine tumor. The nature of the neoplasm, therefore, could not be letermined. According to the relatives' statement the head

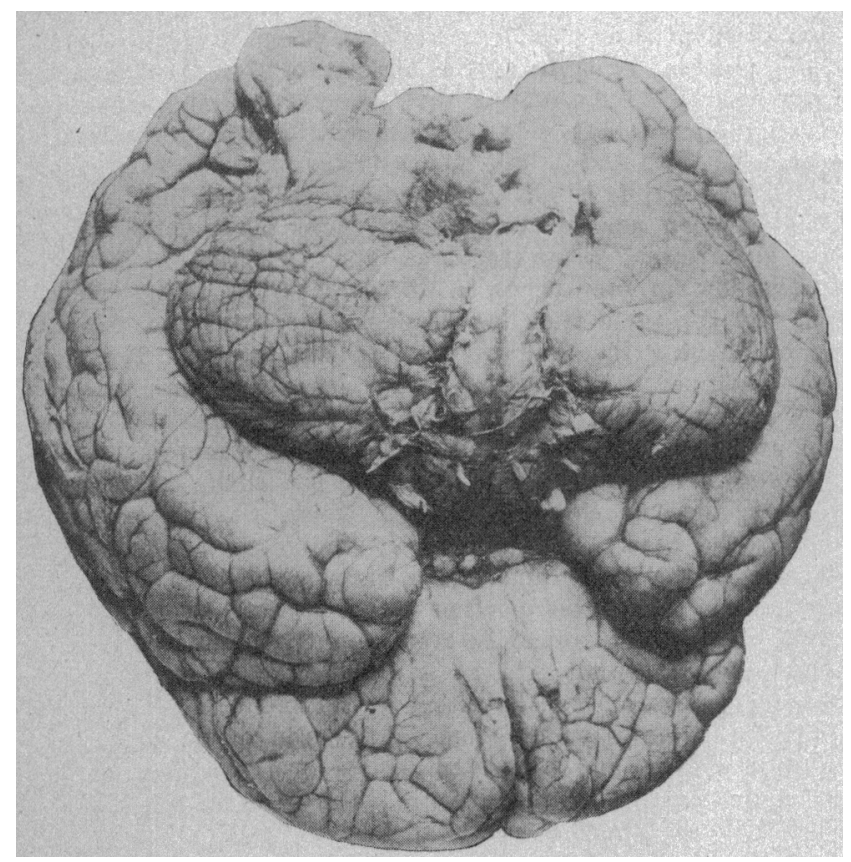

Tuberculous tumor of the cerebellum. Brain of patient in Case ? showing tumor mass on lower aspect of left lobe of cerebellum.

at first was inclined to the left, but three weeks before death turned to the right.

CASE 6.-History.-A. H., girl, aged 16, while playing two years previously, was struck on the head by a brick. The accident was followed by an attack of unconsciousness lasting fifteen minutes. Five hours later she had a severe vomiting spell. During the following three months she suffered from neadache and insomnia. The symptoms gradually subsided ard f for a period of eighteen months she would only occasionally complain of headache in the occipital region. Three months before her death she fell, after which the headache became very severe and it was accompanied by vertigo. She complained of dimness of vision. The head soon assumed a cercain position. It was drawn slightly backward and inclined to the left. As the headache kept on increasing in intensity the patient instinctively sought various positions in anxiety for relief. The head was then held by her, inclined to the right. She claimed that this was the only position which made the headache more tolerable and in which the rertign was almost entirely absent. As soon as she would straighten it and turn it to the left, an intense vertigo would set in and she would fall.

Examination.-Examination of the eyes showed a choked disk in the left and slight optic neuritis in the right. Nystagmus was present on lateral movements of the eyes and equally on both sides. Blindness was rapidly increasing. The gait was somewhat ataxic, but presented no distinct titubation. Sensations were not impaired. Respiration and deglutition were normal. The headache remained severe and the intense vertigo on turning the head to the right remained until death. My diagnosis was a cerebellar tumor on the left. An operation was declined.

Autopsy.-At the autopsy a small soft mass was found on the upper surface of the left cerebellar hemisphere pressing on the vermis. No permission was given for removal of the specimen.

The four cases that came to autopsy are conclusive as to the relation of the attitude of the head to a cerebellar disease. In the two purely clinical cases the symptous of the cerebellar tumors were so typical that there is no doubt as to the diagnosis. In all six of the cases the head assumed a certain persistent position.

In four cases it was turned to the side opposite the lesion during the entire course. In two of them it was inclined at first toward the seat of the lesion, but sometime before the patients died the head changed its position. All the six cases are a good illustration of the fact that in cerebellar diseases, generally speaking, a special attitude of the head is a pathognomonic sign. If I omit the purely clinical cases and confine myself exclusively to the four clinico-anatomic cases I am warranted to say that the field of surgical operations in cerebellar cases should be decided on from the position of the head when the latter is in an abnormal attitude.

Special emphasis is needed in regard to the increase of vertigo and headache when the inclined heads were turned forcibly toward the side of the lesion. This observation is quite novel. In the literature at my disposal I have been able to find one similar but not identical case published by Laruelle. ${ }^{x}$ He localized the tumor in the left cerebellar hemisphere because the head was inclined toward the same side. The tumor, however, was found on the right. The record also shows that each attempt to turn the head to the opposite side provoked an unusual pain.

This case, taken in connection with mine (in which there was particularly vertigo instead of pain in similar manipulations of the head), appears to me quite significant from the standpoint of localization of cerebellar tumors. Its importance is obvious. The clinical observation of my six cases, or at least of the four that came to autopsy, is analogous to the experimental fact observed by Risien Russell. The latter showed that after ablation of one lobe of the cerebellum the trunk of the animal is curved with the concavity to the side of the cerebellar lesion, the side of the face is approximated to the shoulder on the same side.

This peculiar change of position of the head during the evolution of the cerebellar syndrome did not occur in each of my cases at the same period of the disease. In the first case it occurred six months before death; in the fifth only three weeks before the fatai issue. In the third, fourth and fifth cases the head assumed from the beginning the abnormal position with increase of vertigo and headache on turning it to the side of the lesion. In the second case the fixed position of the head on the side opposite to the lesion appeared after the severe symptoms set in.

1. Rev. Neurolog.. 1906. No. 4. 
It is impossible to say why the change of position of the head occurs at various periods in various cases. It is also difficult to say why the change occurs at all and why when the head is turned toward the lesion the vertigo and headache become intolerable. At all events, it is useful in my opinion to retain this fact that in my cases at least the increase of vertigo caused by placing the head in an opposite position was an indication for the seat of the cerebellar tumor. The number of $\mathrm{my}$ calses is certainly too small to draw definite conclusions. Further observations are, of course, necessary. The phenomenon in question, however, is, I believe of a diagnostic value.

In the above-mentioned record of Laruelle the phenomenon escaped the author's notice, but, nevertheless, it was present and verified iny the autopsy.

\section{PATHOLOGIC REPORT OF THE NERVOUS SYSTEM IN A CASE OF SPONDYLOSE RHIZOMELIQUE.*}

JOHN H. W. RHEIN, M.D.

Neurologist to the Howard Hospital, Physician to the Philadelphia Home for Incurables, etc.

$$
\text { PHILADELPHIA. }
$$

A study of the nervous system in cases of spondylose rhizomelique and allied conditions has been made only in a few cases, those of von Bechterew, ${ }^{1}$ Leri, ${ }^{2}$ Reuter, ${ }^{3}$ Fraenkel ${ }^{4}$ and McCarthy, $^{5}$ to which reference will be made later.

In the case which forms the basis for this report the brain, spinal cord, peripheral nerves and muscles were examined, and pathologic changes, though slight, were distinctly observed. The addition of this case, therefore, to the meager literature of the subject, at least so far as a study of the nervous system is concerned, throws some light on a subject about which there exists much diversity of opinion.

History.-The patient, $Z$., was a man, aged 64 , whose history, unfortunately, can not be given, except that he was admitted to the Philadelphia Home for Incurables, Sept. 29. 1903 , and remained there, practically in the same condition as to the symptoms under discussion, until his death on June 18 , 1907. I examined him a week before his death, although I had previously frequently observed him without careful examination.

Examination.-The entire spine, including the articulations with the cranium and pelvis, was ankylosed, presenting the characteristic appearance of so-called "poker-back." There was ankylosis in both hips, knees and shoulders, although this was not complete. The arms could be moved about 30 or 40 degrees at the shoulders. The elbows, hands, ankles and toes were not involved. There was general emaciation at the time of the examination, so that the presence of local atrophies could not be clearly determined. There was pain in both sciatic regions, extending from the knees to the hips, but no pain was complained of elsewhere about the body. The spinal column stood out prominently, and the muscles of the back were probably wasted. Tests for pain, touch and localization

* Read in the Section on Nerrous and Mental Diseases of the American Medical Association, at the Fifty-ninth Annual Session, held at Chicago. June. 1908.

* From the Howard Hospital, and the Department of Neurology and Laboratory of Neuropathology of the University of Pennsy. vania.

1. Deutsch. Ztschr. f. Nervenh.. xv, 45; Neurol. Centralbl. 1892 , p. 426 ; Deutsch. Ztschr. f. Nervenh., $x v, 37$; Ibid., 1897, No. 11, p. 327.

2. Rev. neurol. 1905 , p. 1085, and Revue de méd., 1899, No. 19 p. 597

3. Ztschr, f. Ileilk. 1902. No. 23. p. 83.

4. Fortschr. a d. Geb. d. Iöntgenstrahlen, 1903-4, p. 62

5. New Yolk ired. Jour.. 1905, June. gave negative results. Wwo months before death he developed tuberculosis, which became general, and trom which he finally died.

Autopsy-At the autopsy, when an effort was made to remove the cord, it was discovered that the entire spinal column presented the appearance of one bony mass. It was so hard that it was difficuit to saw through into the spinal canal. On removing the spines and arehes of the vertebræ a considerable amount of caseous material was found on the outer surface of the dura, extending from the lower thoracic, to the lower cervical region. There was no evidence of tuberculous bone disease, or tuberculous abscess, and macroscopic. ally there were no tubercles.

The dura was adherent to the skull, and a few tubercles were found over the convexity of the brain. Both Iungs were infiltrated by tubercles and were the seat of many cavities. The right kidney was also implicated.

The brain and spinal cord, the plantar nerves, sections of the sciatic and smaller sciatic nerves, and some of the muscles from the plantar surface of the foot were preserved for examination. The spinal cord was hardened in Miiller's fluid. and stained by the Weigert method, and in hemalum, acid fuchsin, and thionin.

The white matter of the cord itself showed no abnormality. There was, however, a slight degeneration present in

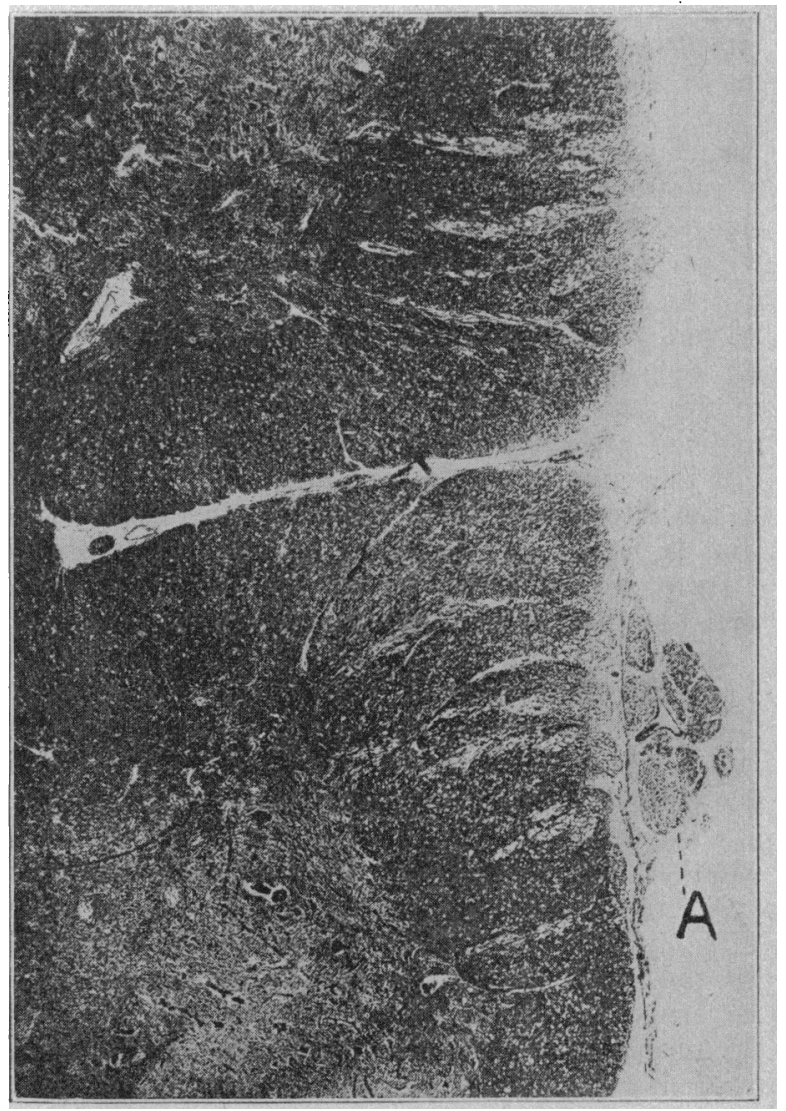

Microscopic findings in a case of spondylose rhizomelique, showing degenerated spinal root at $\Delta$ (Weigert method).

several of the roots. In the lumbar region the right anterior, and left posterior roots were slightly degenerated. In the lower thoracic region there was slight degeneration of the anterior roots. Elsewhere the roots stained normally.

The cells of the spinal cord in the spinal and cervical regions showed the following changes: Some were rounded, had lost their prolongations, and contained an excessive amount of yellow pigment. Clumping of the chromatic substance was pres. ent in some, and in a number of them the nucleus was dislo. cated, and the yellow pigment excessive.

The small sciatic nerve was slightly degenerated in cross sections. An abundance of fatty tissue was seen, and there was increase in the connective tissue. The plantar nerves were also degenerated. The large sciatic nerve was normai. 